Gronenborn, A., Birdsall, B., Hyde, E. I., Roberts, G. C. K., Fenney, J., \& Burgen, A. S. V. (1981a) Nature 290, 273.

Gronenborn, A., Birdsall, B., Hyde, E. I., Roberts, G. C. K., Feeney, J., \& Burgen, A. S. V. (1981b) Mol. Pharmacol. $20,145$.

Hitchings, G. H., \& Smith, S. L. (1980) Adv. Enzyme Regul. 18,349 .

Hyde, E. I., Birdsall, B., Roberts, G. C. K., Feeney, J., \& Burgen, A. S. V. (1980) Biochemistry 19, 3738.

Kraut, J., \& Matthews, D. A. (1986) in Biological Macromolecules and Assemblies (Journak, F., \& McPherson, A., Eds.) Vol. III, Wiley, New York.

Matthews, C. K., \& Sutherland, K. E. (1965) J. Biol. Chem. 240, 2142.

Matthews, D. A., Smith, S. L., Baccarani, D. P., Burchall, J. J., Oatley, S. J., \& Kraut, J. (1986) Biochemistry 25, 4194.

Nakamoto, T., \& Vennesland, B. (1960) J. Biol. Chem. 235, 202.
Pastore, E. J., \& Friedkin, M. (1962) J. Biol. Chem. 237, 3802.

Pattishall, K. H., Acar, J., Burchall, J. J., Goldstein, F. W., \& Harvey, R. J. (1977) J. Biol. Chem. 252, 2319.

San Pietro, A. (1955) J. Biol. Chem. 217, 579.

Seyama, Y., Kasama, T., Yamakawa, T., Kawaguchi, A., \& Okuda, S. (1977) J. Biochem. 81, 1167.

Skold, O., \& Widh, A. (1974) J. Biol. Chem. 249, 4324.

Smith, S. L., \& Burchall, J. J. (1983) Proc. Natl. Acad. Sci. U.S.A. 80, 4619.

Smith, S. L., Stone, D., Novak, P., Baccanari, D. P., \& Burchall, J. J. (1979) J. Biol. Chem. 254, 6222.

Vermersch, P. S., Klass, M. R., \& Bennett, G. N. (1986) Gene $41,289$.

Zolg, J. W., \& Hanggi, U. J. (1981) Nucleic Acids Res. 9, 697.

Zolg, J., Hanggi, U., \& Zachau, H. (1978) Mol. Gen. Genet. $164,15$.

\title{
Reactivity of Parallel-Stranded DNA to Chemical Modification Reagents
}

\author{
Jan Klysik, ${ }^{\ddagger}$ Karsten Rippe, and Thomas M. Jovin* \\ Department of Molecular Biology, Max Planck Institute for Biophysical Chemistry, Postfach 2841, D-3400 Göttingen, FRG \\ Received May 2, 1990; Revised Manuscript Received July 20, 1990
}

\begin{abstract}
Four 25-nt long oligonucleotides containing dA and dT (D1, D2, D3, and D4) which are capable of forming parallel-stranded (ps) or antiparallel-stranded (aps) duplexes have been synthesized [Rippe, K., Ramsing, N. B., \& Jovin, T. M. (1989) Biochemistry 28, 9536-9541]. In the present study, the $\mathrm{OsO}_{4}-$ pyridine complex (Os,py), diethyl pyrocarbonate (DEPC), $\mathrm{KMnO}_{4}$, and the 1,10-phenanthroline-cuprous complex $\left[(\mathrm{OP})_{2} \mathrm{Cu}^{+}\right]$were used to investigate the conformation-dependent reactivity of $\mathrm{ps}$, aps, and single-stranded (ss) oligonucleotides. The products were analyzed by polyacrylamide gel electrophoresis with single-nucleotide resolution. The results confirm the duplex nature of the ps combinations of oligonucleotides and reveal structural differences in comparison with the aps molecules. Under conditions in which ss-DNA is substantially sensitive to Os,py, both the ps and aps duplexes are very unreactive. A similar result was observed with $\mathrm{KMnO}_{4}$ and $\mathrm{DEPC}$, although with the latter reagent the modification pattern of the labeled strands $\mathrm{D} 1^{*}$ and $\mathrm{D} 4 *$ was slightly different for the parallel than for the antiparallel duplex. The $(\mathrm{OP})_{2} \mathrm{Cu}^{+}$ complex efficiently cleaves the aps but not the ps duplex and shows a preference for TAT steps. We also tested the effect of monovalent and divalent cation concentrations on the chemical reactivity of the ps, aps, and ss species. Elevated $\mathrm{NaCl}$ concentration leads to a dramatic increase in the Os,py and $\mathrm{KMnO}_{4}$ modification of ss molecules and the ps, but not the aps, duplex. We attribute the apparent reaction with ps-DNA to a destabilization of this conformation under the conditions of reaction. In contrast, all reactions with DEPC are somewhat depressed at high salt concentration. The effects of $\mathrm{MgCl}_{2}$ and temperature on the chemical reactivity with Os,py were also determined. The helix-coil transition of both the ps and the aps duplexes can be monitored by chemical modification with the $\mathrm{OsO}_{4}$-pyridine reagent.
\end{abstract}

$\mathbf{T}_{\text {he }}$ teristic feature of all right-handed B-type and left-handed Z-type helices. In 1986, N. Pattabiraman presented force field calculations indicating the possibility that a stable duplex composed of $d(A)_{6}$ and $d(T)_{6}$ could form with both strands oriented in the same $5^{\prime}-3^{\prime}$ direction and associated via reverse Watson-Crick base pairing with the glycosidic bonds in a trans

\footnotetext{
'Present address: Department of Biochemistry, University of Alabama, Birmingham, AL.

* Author to whom correspondence should be addressed.
}

orientation (Pattabiraman, 1986). The calculated stability was similar to that of conventional antiparallel DNA, encouraging numerous experimental approaches for examining the existence and properties of parallel-stranded hairpins (van de Sande et al., 1988; Ramsing et al., 1989; Germann et al., 1989; Shchyolkina et al., 1989; Tchurikov et al., 1989) and of parallel-stranded duplexes (Ramsing \& Jovin, 1988; German et al., 1988; Ramsing et al., 1989; Rippe et al., 1989, 1990; Rippe \& Jovin, 1989; Jovin et al., 1990). On the basis of the results available to date, it is clear that DNA can adopt a parallel-stranded (ps) ${ }^{1}$ conformation that is only moderately 
less stable than antiparallel B-DNA. Parallel-stranded DNA (ps-DNA) differs from B-DNA with respect to numerous thermodynamic, spectroscopic, and drug binding characteristics and as a substrate for DNA-specific enzymes.

The present investigation exploited chemical probes developed recently for studying DNA conformations in solution and their transitions in sequences of interest. The objectives were to (i) specify further the structural differences between ps-DNA and aps-DNA, (ii) establish means for identifying the ps conformation in natural sequences, and (iii) demonstrate the utility of the chemical probes in studies of oligonucleotides, a surprisingly undeveloped area of application. Since the synthetic oligonucleotides used in this study were composed exclusively of $\mathrm{dA}$ and $\mathrm{dT}$ nucleotides, the structure-sensitive chemical probes that allow detection of the modification of $\mathrm{dA}$ and $\mathrm{dT}$ residues or cleavage products with single-nucleotide resolution were chosen. Several chemicals, including Os,py [Galazka et al., 1986; Johnston \& Rich, 1985; for a review, see Paleček et al. (1990)], DEPC (Johnston \& Rich, 1985; Herr, 1985), $\mathrm{KMnO}_{4}$ (Borowiec et al., 1987; Lyamichev et al., 1989), and the (OP) ${ }_{2} \mathrm{Cu}^{+}$complex (Kuwabara et al., 1986; Sigman, 1986; Sigman \& Spassky, 1989), can be used to detect structure-dependent hypersensitivity of a given set of bases. Os,py, which adds to the $\mathrm{C} 5-\mathrm{C} 6$ of the pyrimidine rings, site-specifically (Lukäšovâ et al., 1982) modifies singlestranded and distorted regions in DNA, such as the loops of cruciform structures (Lilley \& Paleček, 1984; Klysik et al., 1988), B-Z junctions (Nejedlý et al., 1985; Galazka et al., 1986; Johnston \& Rich, 1985; Klysik et al., 1988), intramolecular triplexes (Vojtišsová \& Paleček, 1987; Hanvey et al., 1988; Voloshin et al., 1988; Vojtǐ̌kovâ et al., 1988; Parniewski et al., 1989), and looped-out bases and bubbles (Bhattacharya \& Lilley, 1989). It reacts primarily with thymines, forming osmate ester derivatives, and more slowly with cytosine and guanine (Klysik et al., 1988). DEPC carbethoxylates the N-7 position of purines in a duplex conformation dependent way (Johnston \& Rich, 1985; Herr, 1985; Klysik et al., 1988). It is reactive with $\mathrm{dA}$ and $\mathrm{dG}$ residues of DNA in the left-handed state and extensively modifies bases within the cruciform loops (Furlong \& Lilley, 1986; Sholten \& Nordheim, 1986). B. DNA is insensitive to modification with either Os,py or DEPC. $\mathrm{KMnO}_{4}$ has also been shown to be useful in studies of DNA conformation (Borowiec et al., 1987; Lyamichev et al., 1989) and is also more reactive with ss than with double-stranded species. Detection of Os,py-, DEPC-, or $\mathrm{KMnO}_{4}$-modified bases is accomplished by piperidine cleavage of the labeled strand and electrophoresis of the resulting products on a sequencing gel next to the Maxam and Gilbert sequencing reactions of the same fragment (Johnston \& Rich, 1985; Herr, 1985; Klysik et al., 1988; Furlong \& Lilley, 1986; Sholten \& Nordheim, 1986). The copper-phenanthroline $\left[(\mathrm{OP})_{2} \mathrm{Cu}^{+}\right]$ complex has been used to distinguish between the conformational details of B-DNA (Kuwabara et al., 1986; Sigman, 1986; Sigman \& Spassky, 1989). A remarkable feature of the $(\mathrm{OP})_{2} \mathrm{Cu}^{+}$-mediated reaction is its mechanism of scission. The minor groove is required for the binding of the complex to DNA and subsequent cleavage, rendering the reagent highly specific for double-stranded B-type helices.

In this report, we present results on chemical modification of ps-, aps-, and ss-DNAs. The set of chemical probes serves

1 Abbreviations: ps, parallel-stranded; ps-DNA, parallel-stranded DNA; aps, antiparallel-stranded; aps-DNA, antiparallel-stranded DNA; ss, single-stranded; $\mathrm{Os}$,py, $\mathrm{OsO}_{4}$-pyridine complex; DEPC, diethyl pyrocarbonate: $(\mathrm{OP})_{2} \mathrm{Cu}^{+}, 1,10$-phenanthroline-cuprous complex; $\mathrm{nt}$, nucleotide(s). to distinguish ps duplexes from their aps counterparts and ss-DNA on the basis of differences in the extents of modification and their dependence on monovalent and divalent cation concentrations and temperature.

\section{Materials and Methods}

Oligonucleotide Synthesis and End Labeling. Oligonucleotides D1, D2, D3, and D4 were synthesized and endlabeled with ${ }^{32} \mathrm{P}$ as described previously (Rippe et al., 1989). After the kinase reaction, oligonucleotides were purified by preparative, denaturing, $15 \%$ polyacrylamide gel electrophoresis followed by extraction and ethanol precipitation (Maniatis et al., 1982).

Duplex Formation. Unless otherwise specified, the DNA strand combinations were mixed in a buffer containing $50 \mathrm{mM}$ $\mathrm{NaCl}, 50 \mathrm{mM}$ Tris- $\mathrm{HCl}, \mathrm{pH} 8.0$, and $10 \mathrm{mM} \mathrm{MgCl}$. The concentration of the unlabeled strand was usually 20 times higher than that of the end-labeled strand $(0.8 \mu \mathrm{M})$. The melting temperature under these conditions was estimated from values determined previously in optical measurements by applying a correction according to the expression

$$
T_{\mathrm{m}}^{-1}=T_{\mathrm{m}, \mathrm{ref}}^{-1}-\left(R / \Delta H_{\mathrm{vH}}\right) \ln \left(4 C_{i} / C_{\mathrm{t}}\right)
$$

where $T_{\mathrm{m}, \mathrm{ref}}$ is the reference $T_{\mathrm{m}}$ of an equimolar mixture with a strand concentration $C_{\mathrm{t}}$ under the same salt conditions as the chemical modification experiment carried out in the presence of an excess concentration, $C_{i}$, of one of the strands. Equation 1 is derived from eq 5 and 14 in Ramsing et al. (1989) and the following expression for the dissociation constant $K$ in the case of one strand being in excess:

$$
K \approx C_{i} \alpha /(1-\alpha)
$$

where $\alpha$ is the fractional degree of transition to the coil form. The values of the van't Hoff enthalpy difference $\Delta H_{\mathrm{vH}}$ and $T_{\text {m,ref }}$ for the helix-coil transition in $10 \mathrm{mM} \mathrm{MgCl}_{2}$ were those determined previously from measurements of absorption hyperchromicity (Rippe et al., 1989). The samples were heated to $70^{\circ} \mathrm{C}$ for $10 \mathrm{~min}$ and cooled slowly to room temperature before starting the reaction, the volume of which was usually $50 \mu \mathrm{L}$

$\mathrm{OsO}_{4}-\mathrm{Pyridine} \mathrm{Modification}$. Modification with Os,py was performed according to Galazka et al. (1986). The $25 \mathrm{mM}$ $\mathrm{OsO}_{4}$ (Sigma) stock solution was kept frozen $\left(-20^{\circ} \mathrm{C}\right)$. DNA solutions in the appropriate buffer were supplemented with pyridine $(2 \% \mathrm{v} / \mathrm{v})$, and the reaction was started by adding $\mathrm{OsO}_{4}$ stock solution to a final concentration of $2 \mathrm{mM}$. After $2 \mathrm{~min}$, the reaction was stopped by adding 4 volumes of ethanol. Then the DNA was pelleted, washed with $75 \%$ ethanol, dissolved in $1 \mathrm{M}$ piperidine, and heated at $90^{\circ} \mathrm{C}$ for $30 \mathrm{~min}$. The samples were dried in a Savant vacuum centrifuge, dissolved in formamide, and loaded on a $15 \%$ polyacrylamide [19:1 acrylamide/bis(acrylamide)] sequencing gel. Exposure times of the Kodak XAR-5 X-ray film were adjusted according to the number of counts per lane loaded on each individual gel. In reference to the reactions with Os,py and the other reagents, the terms overmodification and overreaction are used to indicate that the extent of cleavage greatly exceeded the limit of a single site per molecule, thereby biasing the distribution.

DEPC Modification. Modifications with DEPC were performed as described previously (Klysik et al., 1988). Solutions of the synthetic oligonucleotides in appropriate buffers were made as in the case of Os,py reactions except that $\mathrm{OsO}_{4}$ and pyridine were omitted. Reactions were started at room temperature by adding one-tenth of the sample volume of 


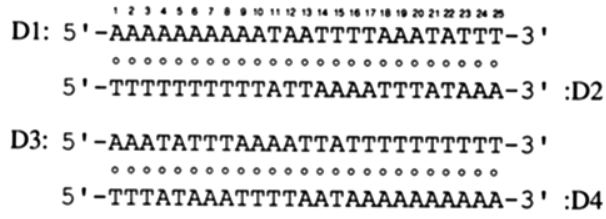

D1: 5 ' -AAAAAAAAAATAATTTAAATATTT-3 '

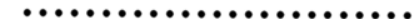
$3^{\prime}$-TTTTTTTTTATTAAAATTATAAA-5' :D3

D2: 5 '-TTTTTTTTTTATTAAAATTTATAAA-3 '

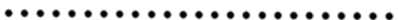

$3^{\prime}$-AAAAAAAAAATAATTTTAAATATTT-5' :D4

FIGURE 1: Sequences of oligonucleotides and their duplexes. The Watson-Crick base pairs of the antiparallel duplex aps-D1.D3 and aps-D2-D4 are shown by the symbol (0) and the reverse Watson-Crick (trans Crick-Watson) base pairs of the parallel-stranded duplexes (ps-D1·D2, ps-D3.D4) by the symbol (O). (A) Parallel-stranded duplexes ps-D1-D2 and ps-D3-D4. (B) Antiparallel-stranded duplexes aps-D1·D3 and aps-D2.D4.

DEPC and vortexing. Modification was terminated by precipitation of DNA with 4 volumes of ethanol. Further workup was as in the case of Os,py modification.

$\mathrm{KMnO}_{4}$ Reaction. Reactions with $\mathrm{KMnO}_{4}$ were performed according to Yeung et al. (1988). DNA was exposed to $\mathrm{KMnO}_{4}\left(80 \mu \mathrm{g} \mathrm{mL}^{-1}\right)$ for $15 \mathrm{~min}$ at room temperature, and the reaction was terminated by adding $10 \mu \mathrm{L}$ of allyl alcohol. After precipitation with ethanol, the DNA was treated with piperidine, heated to $90^{\circ} \mathrm{C}$ for $30 \mathrm{~min}$, dried, and loaded on the sequencing gel after dissolving in formamide.

$(\mathrm{OP})_{2} \mathrm{Cu}^{+}$Reaction. DNA cleavage by phenanthrolinecopper complex was done in $50 \mathrm{mM}$ Tris- $\mathrm{HCl}, \mathrm{pH} 7.2,2 \mathrm{mM}$ $\mathrm{MgCl}_{2}, 4.8 \mathrm{mM}$ 3-mercaptopropionic acid, $340 \mu \mathrm{M} \mathrm{1,10-}$ phenanthroline (Sigma), and $80 \mu \mathrm{M} \mathrm{CuSO}_{4}$. The reaction was stopped by adding 2,9-dimethyl-1,10-phenanthroline (Sigma) to a final concentration of $2 \mathrm{mM}$. After lyophilization, the samples were dissolved in formamide and loaded on a sequencing gel.

Densitometric Tracings of the Autoradiograms. The X-ray films were transilluminated and the transmitted images acquired with a Series 200 slow-scan CCD camera (Photometrics, Tucson, AZ) with a dynamic range of 14 bits and a spatial resolution of 4.2 pixels $\mathrm{mm}^{-1}$. The images were processed on an Apple Macintosh IIcx computer using combinations of the programs TCL-Image (Delft Center for Image Processing, distributed by Multihouse, Amsterdam; the Macintosh version was kindly supplied by Dr. I. T. Young) and Image (W. Rasband, National Institutes of Health, Bethesda, MD). Optical densities (OD) were computed after flat-field correction, and the central 10 lines of each lane were averaged (for the scan plots) or depicted in a 3-D representation. Good linearity was obtained up to an optical density of 1.5 . Plots were generated with the commercial programs Passage and DeltaGraph; superposed scans were displaced vertically for enhanced clarity.

\section{RESULTS AND DISCUSSION}

The physicochemical and biochemical characteristics of the 25-nt long oligonucleotides D1, D2, D3, and D4 and their duplexes have been reported previously (Rippe et al., 1989; Ramsing et al., 1989; Rippe \& Jovin, 1989; Jovin et al., 1990). Figure 1 depicts the possible combinations of oligonucleotides that lead to the formation of ps or aps duplexes. Thus, oligonucleotides D1 + D2 and D3 + D4 mixed in stoichiometric amounts form ps duplexes (Figure 1A), whereas D1 + D3 and D2 + D4 form conventional aps helices (Figure 1B). The other

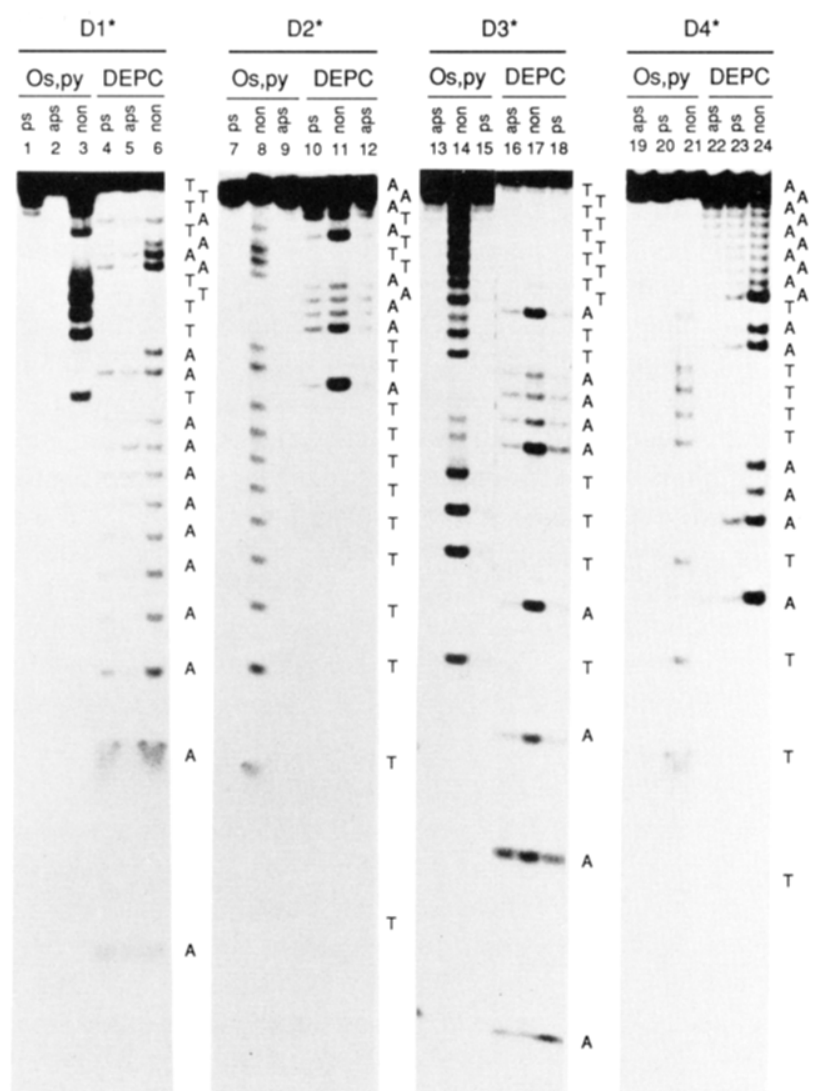

FIGURE 2: Autoradiograph from sequencing gel of Os,py- and DEPC-modified duplexes (aps and ps) and nonpairing (non) species. The modification reactions contained mixtures of the given labeled strand (indicated by asterisks) and about 20 -fold excess of the unlabeled strand necessary to constitute the ps, aps, or nonpairing combination (cf. Figure 1). For example, in the first panel, $\mathrm{Dl}^{*}$ is labeled, and the lanes denoted with ps (lane 1), aps (lane 2), and non (lane 3 ) correspond to the combinations ps-D1*.D2, aps-D1*.D3, and $\mathrm{D}^{*}+\mathrm{D} 4$. Modifications were performed in $50 \mathrm{mM} \mathrm{NaCl}, 50 \mathrm{mM}$ Tris- $\mathrm{HCl}, \mathrm{pH} 8.0$, and $10 \mathrm{mM} \mathrm{MgCl}$ at room temperature. After modification and piperidine cleavage, the samples were run on a $15 \%$ sequencing gel before autoradiography. Each lane contained the same number of counts loaded. Modification patterns obtained for single-stranded $\mathrm{D1}^{*}, \mathrm{D} 2^{*}, \mathrm{D} 3^{*}$, and $\mathrm{D}^{*}$ oligonucleotides (data not shown) were identical with those resulting from reactions of nonpairing mixtures $\mathrm{Dl}^{*}+\mathrm{D} 4, \mathrm{D} 2 *+\mathrm{D} 3, \mathrm{D} 2+\mathrm{D} 3^{*}$, and $\mathrm{D} 1+\mathrm{D} 4^{*}$.

combinations, D1 + D4 or D2 + D3, are not complementary in either orientation; neither parallel nor antiparallel duplexes have been detected (Rippe et al., 1989).

In this study, the duplexes preformed in vitro were subjected to chemical modification and chemical cleavage. The collected data were compared with results obtained by similar treatment of nonpairing combinations of oligonucleotides or of one strand employed as single-stranded references.

Modifications of ps-, aps-, and ss-DNA with Os,py and $D E P C$. Upon mixing labeled D1 fragment (D1*) with unlabeled D2 or D3, the ps or aps duplexes ps-D1*.D2 and apsD1*.D3 are formed under the buffer conditions used $(10 \mathrm{mM}$ $\mathrm{MgCl}_{2}, 50 \mathrm{mM} \mathrm{NaCl}$, and $50 \mathrm{mM}$ Tris- $\mathrm{HCl}, \mathrm{pH} \mathrm{8.0)}$ (Rippe et al., 1989). D1* mixed with D4 remains single-stranded (ss); that is, duplex formation is not detected. In a similar way, the end-labeled D2 (D2*) can be used to generate ps-D1.D2* and aps-D2*.D4, or when mixed with D3, to establish a single-stranded control. The same combinations can be produced with labeled D3* and D4*.

The reactivities of the given combinations with Os,py and DEPC are shown in Figure 2. As expected, both chemicals react extensively with the unpaired mixture of the oligonucleotides, or the single-stranded oligonucleotides (data not 
shown). Os,py overreacts with dT, whereas DEPC overmodifies $\mathrm{dA}$ residues. The aps or ps duplexes, however, are much less sensitive to these chemicals, regardless of which strand is labeled and analyzed. In particular, Os,py shows virtually no reaction with aps DNA, but a slight reactivity can be detected for the ps counterparts on the original autoradiographs. The differences between modification intensities of the given bands for aps or ps duplexes and ss or nonpaired species obtained with DEPC are also clear. Most reactive is the nonpairing combination of oligonucleotides; the aps and ps duplexes are less sensitive to this chemical. Some minor but reproducible differences between the intensities of individual bands derived from $\mathrm{Dl}^{*}$ and $\mathrm{D}^{*}$ strands forming aps or ps duplexes are also apparent (cf. Figure 1, lanes 4, 5 and $22,23)$. These results are consistent with previous studies (Rippe et al., 1989; Ramsing et al., 1989), and we conclude that the appropriate combinations of synthetic oligonucleotides form aps or ps duplexes that are less accessible to chemicals such as Os,py or DEPC than DNA in a single-stranded conformation.

Effect of $\mathrm{NaCl}$ on Os,py and DEPC Reactivity. The stability of double-stranded ps or aps DNA depends on a number of physicochemical factors including the counterion concentration in the DNA solution. Salt-induced changes in DNA conformation such as in the $\mathrm{B}-\mathrm{Z}$ transition are very well documented (Rich et al., 1984; Jovin et al., 1987). Thus, it was of interest to compare the change in the Os,py and DEPC reactivity to aps and ps duplexes and ss-DNA as a function of the salt concentration. An increase in $\mathrm{NaCl}$ concentration up to 4 or $5 \mathrm{M}$ results in a slight increase in the extent of Os,py modification of the aps-D1·D3* duplex [Figure 3 (top), lanes 13-16; and Figure 3 (bottom), panel D]. Interestingly, a substantial increase in reactivity of $1 \mathrm{dT}$ residue (closest to the $5^{\prime}$ end, $\mathrm{T}_{4}$; see Figure $1 \mathrm{~A}$ ) out of the $16 \mathrm{~T}$ residues present on this strand is evident. The behavior of the ps duplex is substantially different. At 0.5 or $1.5 \mathrm{M} \mathrm{NaCl}$, weak Os,py modifications are observed [Figure 3 (top), lanes 21 and 22; Figure 3 (bottom), panel F]. Upon further increases in salt concentration, the ps duplex is overmodified, as reflected by the diminution of the radioactive material at the position of the intact fragment (top of the gel) [Figure 3 (top), lanes 23 and 24; Figure 3 (bottom), panel F]. The nonpairing combination of the oligonucleotides D2 + D3* [Figure 3 (top), lanes 17-20; Figure 3 (bottom), panel E] as well as D3* alone (data not shown) is also sensitive to the salt increase and become overmodified at the highest $\mathrm{NaCl}$ concentration used. We conclude that elevated salt concentrations increase the intrinsic reactivity of the $\mathrm{OsO}_{4}$-pyridine reagent. Modification of aps-D1.D3* by Os,py changes only slightly as a function of salt concentration; thus, the different behavior of the psD3*.D4 duplex must reflect distinctive features of the parallel-stranded conformation. In fact, measurements of absorption hyperchromicity show that high salt concentrations reduce the thermodynamic stability of the ps helix. For example, the $T_{\mathrm{m}}$ of ps-D1.D2 and ps-D3.D4 in $1.6 \mathrm{M} \mathrm{NaCl}$ is $46^{\circ} \mathrm{C}$ (Rippe et al. 1989) but decreases to $32^{\circ} \mathrm{C}$ in $4.9 \mathrm{M}$ $\mathrm{NaCl}$ and $10 \mathrm{mM} \mathrm{MgCl}$. In addition, the helix-coil transition is less cooperative; $\Delta H_{\mathrm{vH}}$ decreases by $\sim 30 \%$. These changes do not reflect a conformational transition in the native state as judged from the invariant wavelength-dependent hyperchromicity pattern (Ramsing et al., 1989; Rippe et al., 1989) and from circular dichroism spectra. (Experimental and theoretical studies of these high salt effects on ps-DNA will be reported elsewhere.) Due to the reduced cooperativity of the helix-coil transition of ps-DNA, we calculate a value of
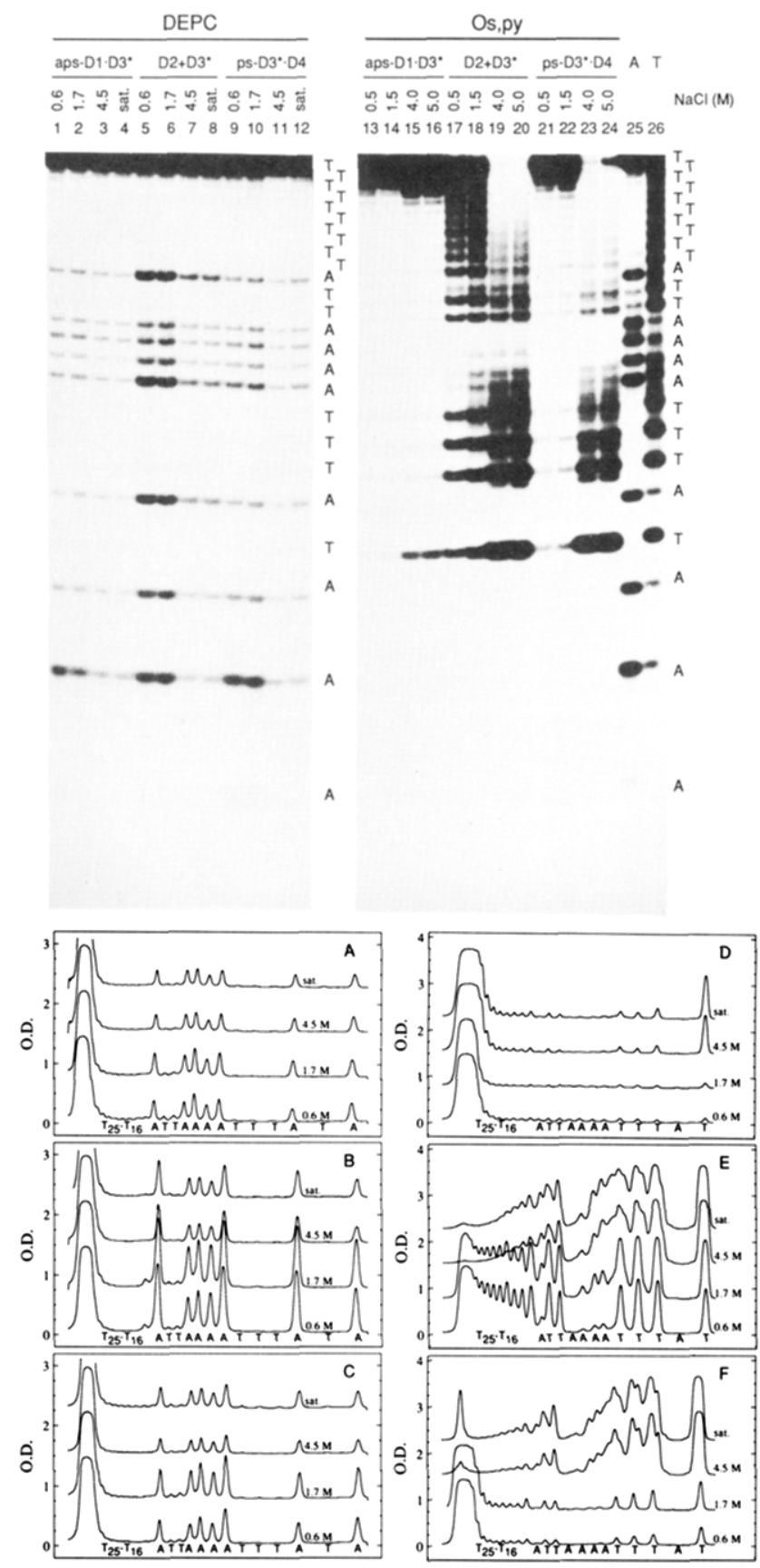

FIGURE 3: DEPC and $\mathrm{OsO}_{4}$,py modification of aps-D1.D3*, psD3*.D4, and nonpairing (non) combination of oligonucleotides D2 $+\mathrm{D}^{*}$ as a function of increasing $\mathrm{NaCl}$ concentration. (Top) Autoradiograph from sequencing gel of reaction products. Reactions were performed at room temperature in the buffer containing $50 \mathrm{mM}$ $\mathrm{NaCl}, 50 \mathrm{mM}$ Tris- $\mathrm{HCl}, \mathrm{pH} 8.0$, and $10 \mathrm{mM} \mathrm{MgCl}$ supplemented with the indicated concentration of $\mathrm{NaCl}$. The abbreviation "sat." refers to the solution saturated with $\mathrm{NaCl}$ and $\mathrm{A}$ and $\mathrm{T}$ to the products of the Maxam-Gilbert sequencing reaction for adenines and thymines, respectively. (Bottom) Densitometric scans of the autoradiograph presented in the top part of the figure. A-C show the results for the DEPC modification: (A) aps-D1·D3*; (B) D2 + D3*; (C) ps-D3*.D4. Panels D-F show the results for the modification with the $\mathrm{OsO}_{4}$ pyridine reagent. (D) aps-D1·D3*; (E) D2 + D3*; (F) ps-D3*.D4.

$\alpha$ at $25^{\circ} \mathrm{C}\left(7^{\circ} \mathrm{C}\right.$ below the optically determined $\left.T_{\mathrm{m}}\right)$ of $\sim 0.2$, indicating that a considerable fraction is in the ss coil state and thereby susceptible to the Os,py reagent. The apparent $T_{\mathrm{m}}$ of the ps duplex would be depressed still further due to the increased reactivity of the unlabeled single strand in excess to Os,py at high $\mathrm{NaCl}$ concentrations. That is, a continuous diminution of $C_{i}$ during the reaction would have the effect of shifting the transition curve to lower temperatures (eq 1 and 


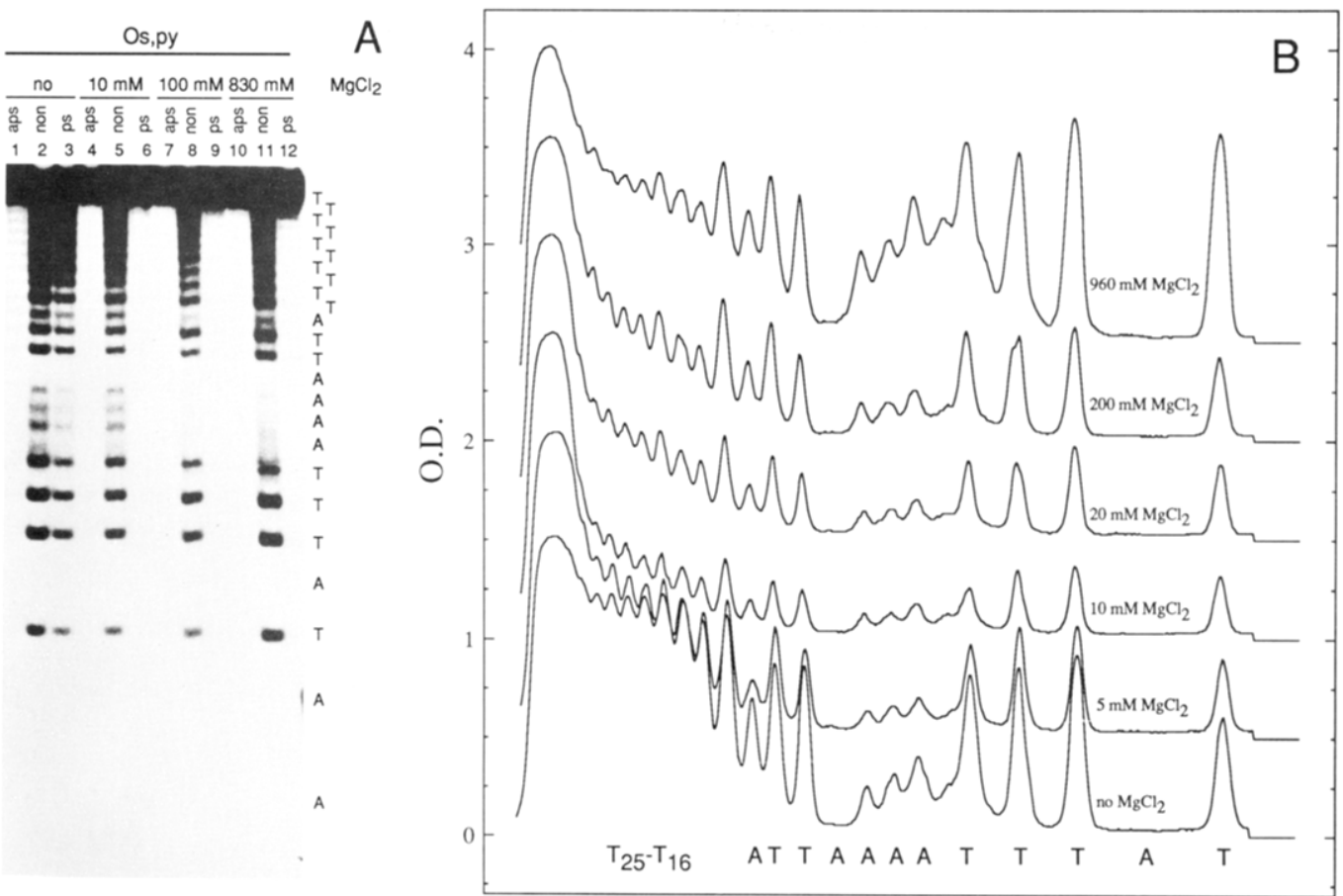

FIGURE 4: Effect of $\mathrm{MgCl}_{2}$ on Os,py reactivity. (A) Autoradiograph of products from reaction with aps-D1·D3* (aps), ps-D3*.D4 (ps), and D2 + D3* (non) separated on a sequencing gel. Modifications were conducted in a buffer containing $50 \mathrm{mM}$ Tris- $\mathrm{HCl}$, $\mathrm{pH} 8.0$, and $50 \mathrm{mM}$ $\mathrm{NaCl}$ at room temperature after supplementing the mixture with the indicated concentration of $\mathrm{MgCl}_{2}$. (B) Effect of $\mathrm{MgCl}_{2}$ on Os,py reactivity on single-stranded D3*. The experiment was performed essentially as in (A). The plot derives from the quantitation of the autoradiograph.

2). In contrast, the $T_{\mathrm{m}}$ of the aps duplexes is much less affected by the high salt condition, decreasing from $60^{\circ} \mathrm{C}$ at $1.6 \mathrm{M} \mathrm{NaCl}$ (Rippe et al., 1989) to $58^{\circ} \mathrm{C}$ in $4.9 \mathrm{M} \mathrm{NaCl} / 10$ $\mathrm{mM} \mathrm{MgCl}$ (data not shown), a value well above the reaction temperature of $25^{\circ} \mathrm{C}$. In addition to the effect of high salt concentration, the $\mathrm{OsO}_{4}$-pyridine reagent itself may destabilize the ps helix (see Helix-Coil Transition of ps and aps Duplexes Monitored by $\mathrm{OsO}_{4}$-Pyridine Modification). In summary, we interpret the apparent hyperreactivity of the ps-DNA with Os,py at high salt concentration as the result of an increase in the Os,py reactivity of ss-DNA, and a destabilization of the ps duplex with a concomitant reduction of the helix-coil transition cooperativity.

Substantially different effects of increasing $\mathrm{NaCl}$ concentration can be demonstrated with DEPC (Figure 3). Little change in sensitivity is detected with the ps duplex [Figure 3 (top), lanes 9-12; Figure 3 (bottom), panel C], the aps duplex [Figure 3 (top), lanes 1-4; Figure 3 (bottom), panel A], and the nonpairing combination D2 + D3* [Figure 3 (top), lanes 5-8; Figure 3 (bottom), panel B], all of which show a slight decrease in reactivity. The reaction of DEPC with unpaired $\mathrm{dA}$ is much less than that of Os,py with unpaired dT residues [Figure 2; Figure 9 in Bhattacharya and Lilley (1989)]. Thus, the differences in modification of the helix and coil forms, already relatively minor at low salt concentration, are reduced even further under high salt conditions. We conclude that DEPC is an effective probe of DNA conformation only at moderate ionic strength.

Effect of $\mathrm{MgCl}_{2}$ on Reactivity of ps-, aps-, and ss-DNA with Os,py. We tested the effect of $\mathrm{Mg}^{2+}$ ions on the Os,py reactivity of ss DNA (D3* or D2 + D3*) and the ps-D3*.D4 and aps-D1·D3* duplexes (Figure 4A). From the densitometric trace of the autoradiogram of the sequencing gel shown in Figure 4B, it is clear that the D3* oligonucleotide at first shows a slightly lower reactivity as the $\mathrm{MgCl}_{2}$ concentration increases. Still higher $\mathrm{MgCl}_{2}$ concentrations cause a slight elevation in Os,py modification, but the changes in the intensities of the bands are relatively small.
In the absence of $\mathrm{Mg}^{2+}$, the ps duplex displays a modification rate that is only slightly lower than that obtained for the nonpairing combination of oligonucleotides, that is, substantially higher than in the case of the aps complex (Figure $4 \mathrm{~A}$, lanes 1-3). This result can be interpreted in terms of the thermodynamic stability of the ps duplex as compared with the aps reference, and correlates well with previous findings (Rippe et al., 1989). The salt conditions used are high enough to allow aps but not ps duplex formation at room temperature $\left(22{ }^{\circ} \mathrm{C}\right)$. The experiments were performed in the buffer containing $50 \mathrm{mM} \mathrm{NaCl}$ and $50 \mathrm{mM}$ Tris- $\mathrm{HCl}, \mathrm{pH} 8$, buffer. The $T_{\mathrm{m}}$ for aps-D1·D3 under these conditions was previously determined to be around $40^{\circ} \mathrm{C}$, whereas the $T_{\mathrm{m}}$ for the psD3.D4 duplex is about $22^{\circ} \mathrm{C}$ (Rippe et al., 1989).

Due to the increased stability of both duplex structures, the aps- and ps-DNAs are less sensitive to Os,py modification than the nonpairing combination of oligonucleotides at all $\mathrm{Mg}^{2+}$ concentrations used (Figure 4A, lanes 4-12). In contrast to the findings obtained with the $\mathrm{NaCl}$ experiment (Figure 3), no dramatic increase in sensitivity is observed over the range of $\mathrm{MgCl}_{2}$ concentrations.

Helix-Coil Transition of ps and aps Duplexes Monitored by $\mathrm{OsO}_{4}-$ Pyridine Modification. As demonstrated in the previous sections, the Os,py reactivity toward the ps duplex and ss-DNA is greatly influenced by $\mathrm{NaCl}$ (Figure 3). We expected that the modification kinetics might be relatively invariant over a substantial range of temperature. In fact, the Os,py reagent was used in earlier studies of temperature-dependent cruciform and triple-stranded DNA formation (Klysik et al., 1988; Hanvey et al., 1989). We addressed the question of whether one can monitor the helix-coil transitions of ps and aps duplexes by detecting the change in sensitivity of DNA to Os,py modification. Results of such an experiment are shown in Figure 5. It is apparent that little change in the elevated modification rate can be detected with the nonpairing combination of D2 + D3* oligonucleotides over the temperature range $22-62{ }^{\circ} \mathrm{C}$ [Figure 5 (top), lanes 9-16]. Substantial increases in Os,py sensitivity occur, however, for ps 

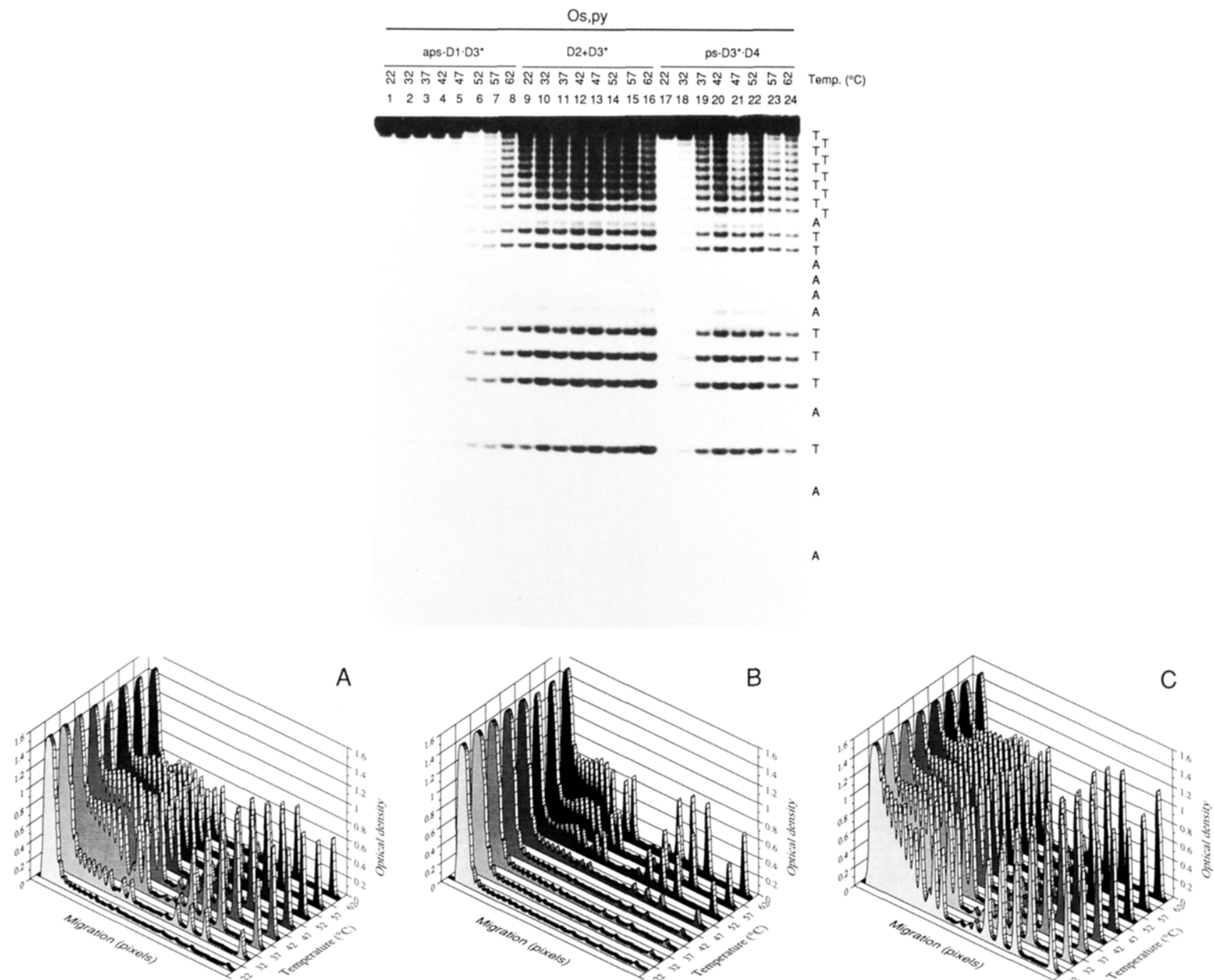

FIGURE 5: Effect of temperature on thermal stability and Os,py reactivity of aps, ps, and nonpairing combinations of oligonucleotides. (Top) Autoradiograph of the sequencing gel. The experiment was made and samples were worked up essentially as described in the legend to Figure 2. Os,py modification was performed after equilibration of the samples at the indicated temperature for 5 min. (Bottom) Scans of the autoradiograph shown in the top of the figure in a 3-D representation. (A) ps-D3*.D4. (B) aps-D1·D3*. (C) D2 + D3*.

(lanes 17-24) and aps [Figure 5 (top), lanes 1-8] duplexes. Quantitation of the densitometric tracings of the autoradiograph of the sequencing gel [Figure 5 (bottom)] allows us to derive apparent $T_{\mathrm{m}}$ values, which are about $35^{\circ} \mathrm{C}$ for the ps duplex and $55^{\circ} \mathrm{C}$ for the aps duplex. The latter determination is $2{ }^{\circ} \mathrm{C}$ lower than the $T_{\mathrm{m}}$ of $57^{\circ} \mathrm{C}$ estimated from eq 1 and 2. In the case of ps-DNA, the apparent $T_{\mathrm{m}}$ obtained by chemical modification is $\sim 7^{\circ} \mathrm{C}$ lower than the predicted value of $42^{\circ} \mathrm{C}$. The greater discrepancy with ps-DNA may in part reflect the reduced cooperativity of the helix-coil transition. In addition, it is possible that the denaturation kinetics of ps-DNA are substantially more rapid than that of the aps duplex, thereby leading to a continuous readjustment of the equilibrium during the reaction period in favor of the more reactive ss species. As a consequence, the extent of reaction would be greater than that corresponding to the initial distribution of the helical $(1-\alpha)$ and the coil $(\alpha)$ forms (eq 2). Finally, we consider the possibility that the Os,py reagent exerts a direct destabilizing effect on helical DNA, as reported previously (Lukášovã et al., 1982) for a range of pyridine concentrations encompassing our reaction conditions. One might presume that the perturbing influence of the reagent increases with temperature and that it is differentially expressed in the case of the ps-DNA. The alternative reagent, $\mathrm{OsO}_{4}$ complexed with equimolar $2,2^{\prime}$-bipyridine (Paleček et al., 1987), may be superior to Os,py in this respect. $\mathrm{KMnO}_{4}$ Reactivity of aps and ps Duplexes: Salt Effect. $\mathrm{KMnO}_{4}$ is another chemical which manifests a much higher reactivity toward ss-DNA than double-stranded molecules and is widely used in studying the conformation of DNA (Borowiec et al., 1987; Lyamichev et al., 1989). It oxidizes mainly dT residues, allowing the cleavage of the chain at the modified bases by piperidine treatment (Pope \& Sigman, 1984).

As demonstrated in Figure 6A both aps and ps duplexes are slightly sensitive to this chemical under the chosen experimental conditions. The nonpairing combination of the oligonucleotides, however, is much more reactive. Sensitivity of $\mathrm{KMnO}_{4}$ reaction to increasing $\mathrm{NaCl}$ concentration is also apparent (Figure 6B-D), and similar to that observed for Os,py (Figure 3). Clearly, the ps (Figure 6D) as compared to aps duplex (Figure 6B) shows much greater reactivity at the highest $\mathrm{NaCl}$ concentration used.

Copper-1,10 Phenanthroline Reagent Discriminates between aps and ps Duplexes. The 1,10-phenanthroline-copper complex after reduction to cuprous complex $\left[(\mathrm{OP})_{2} \mathrm{Cu}^{+}\right]$can be oxidized under aerobic conditions to generate hydrogen peroxide via a superoxide intermediate, that in turn leads to copper-bound hydroxyl radical formation. The (OP) ${ }_{2} \mathrm{Cu}^{+}$ complex binds to the minor groove of DNA in a sequence- and secondary structure-dependent manner. The hydroxyl radicals 

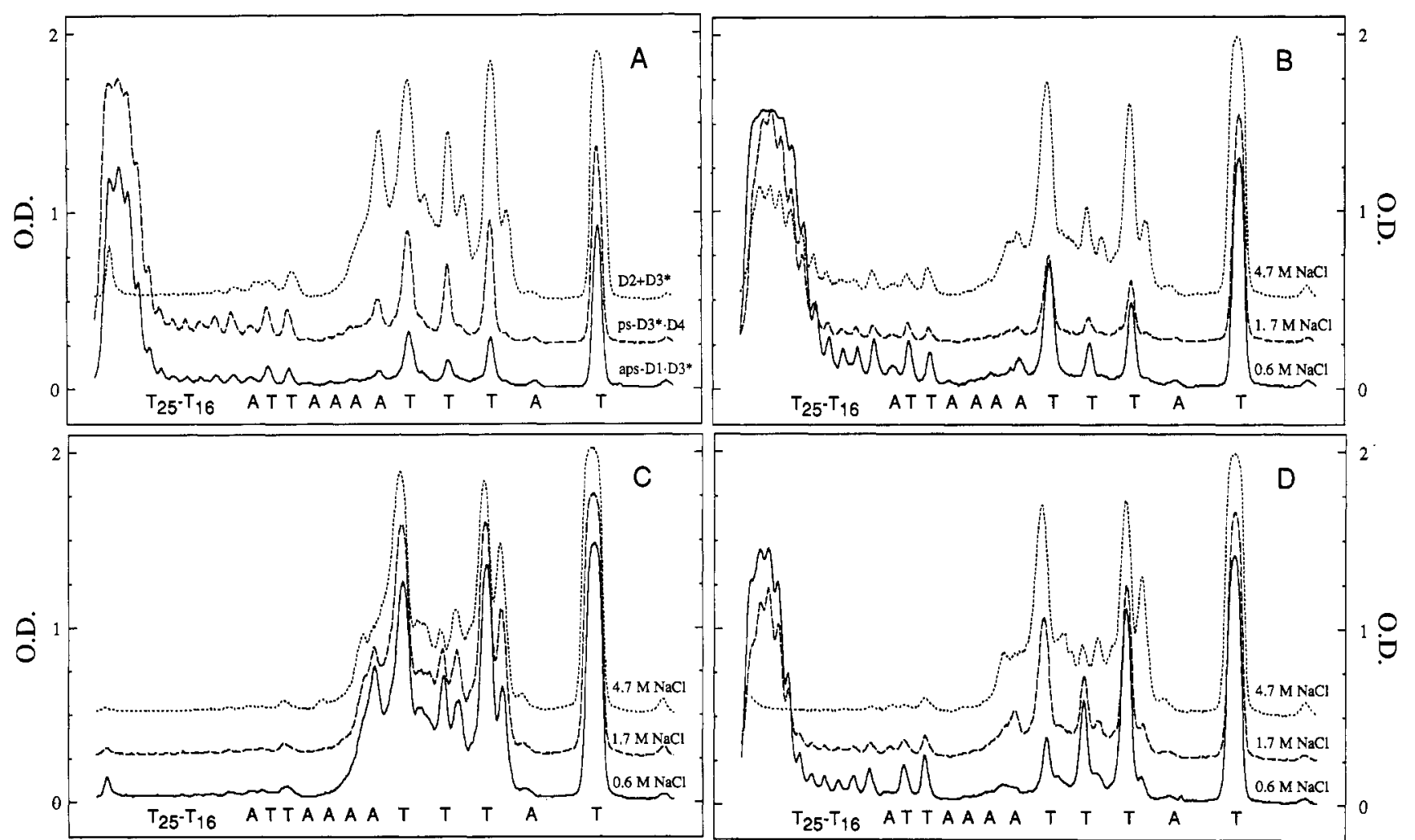

FIGURE 6: Reactivity of ps, aps, and nonpairing combinations of oligonucleotides to $\mathrm{KMnO}_{4}$ as revealed by densitometric tracings. Reactions with all combinations of oligonucleotides were conducted at room temperature in $50 \mathrm{mM}$ Tris- $\mathrm{HCl}, \mathrm{pH} 8.0$, and $10 \mathrm{mM} \mathrm{MgCl}$ in addition to the given $\mathrm{NaCl}$ concentration. (A) All combinations in $50 \mathrm{mM} \mathrm{NaCl}$. (B) aps-D1.D3* in 0.6, 1.7, and 4.7 $\mathrm{M} \mathrm{NaCl}$. (C) D2 + D3* in $0.6,1.7$, and $4.7 \mathrm{M} \mathrm{NaCl}$. (D) ps-D3*.D4 in $0.6,1.7$, and $4.7 \mathrm{M} \mathrm{NaCl}$.

attach to the deoxyribose moiety, leading to the scission of the phosphodiester bonds. This efficient chemical nuclease has been shown to cleave B-DNA and A-DNA at a reduced rate, but not Z-DNA and single-stranded species (Pope \& Sigman, 1984; Sigman et al., 1985).

It was of interest to determine with single-nucleotide resolution whether (OP) ${ }_{2} \mathrm{Cu}^{+}$complex could actually discriminate between the aps and ps duplexes. The aps and ps duplexes as well as ss oligonucleotides and the mixture of nonpairing oligonucleotides were cleaved with this chemical, and the resulting products were subjected to sequencing gel electrophoresis (Figure 7A,B). As expected, the most efficient cleavage occurs in the case of aps duplexes. The predominant cleavage sites are located at the two TAT steps on the apsD1.D3* (Figure 7A) or at the TAT and at one out of two TAA steps on the aps-D2.D4* duplex (Figure 7B). The TAT steps on B-DNA helix are known to be the most sensitive sites for (OP) ${ }_{2} \mathrm{Cu}^{+}$cleavage (Veal \& Rill, 1988). Little or no degradation of the D3* or D4* oligonucleotides occurs when ps DNA is formed with unlabeled D4 and D3, respectively. The cleavage pattern obtained for ss-D3* and ss-D4* or for the nonpairing combinations (D2 + D $3^{*}$ and $\mathrm{D} 1+\mathrm{D} 4^{*}$ ) is still different from that obtained for their aps and ps counterparts. For example, ss-D3* or D2 + D3* are slightly sensitive to (OP) ${ }_{2} \mathrm{Cu}^{+}$scission at the TAT step closest to the $3^{\prime}$ end of D3*. The second TAT step closer to the $5^{\prime}$ end remains insensitive. (In aps-D 1.D 3*, both TAT sites are sensitive.) The ss-D4* and D $1+D 4 *$ cleavage patterns are also identical and differ from the pattern obtained for the aps-D2.D4* duplex. The TAT and $5^{\prime}$-TAA steps efficiently cleaved in the aps duplex formed with D4* seem to be much less sensitive in the case of ss-D4*, on which new sites appear at the second TAA sequence that is closer to the $3^{\prime}$ end (Figure 7B). Previous work has demonstrated that the $(\mathrm{OP})_{2} \mathrm{Cu}^{+}$reagent does not cleave ss-DNA (Pope \& Sigman, 1984; Sigman et al., 1985).
Table I: Reactivity of Chemical Reagents with Different Combinations of Oligonucleotides ${ }^{a}$

\begin{tabular}{|c|c|c|c|c|c|}
\hline reagent & {$\left[\mathrm{MgCl}_{2}\right]$} & {$[\mathrm{NaCl}]$} & aps & ps & $s s^{b}$ \\
\hline \multirow[t]{3}{*}{ Os,py } & low & low & - & $-c$ & ++ \\
\hline & low & high & + & $+++^{d}$ & +++ \\
\hline & high & low & - & - & ++ \\
\hline \multirow[t]{2}{*}{ DEPC } & low & low & $t^{e}$ & te & ++ \\
\hline & low & high & $+r$ & $+f$ & + \\
\hline \multirow[t]{2}{*}{$\mathrm{KMnO}_{4}$} & low & low & + & + & $++t$ \\
\hline & low & high & $+t$ & +++ & +++ \\
\hline$(\mathrm{OP})_{2} \mathrm{Cu}^{+}$ & low & low & $++g$ & - & + \\
\hline
\end{tabular}

${ }^{a}$ Relative activities at $22^{\circ} \mathrm{C}:+++$, very high; ++ , high; + , moderate; -, none or very low, ${ }^{b}$ Single strands D1, D2, D3, and D4 or nonpairing combinations D2 + D3 and D1 and D4. ${ }^{C}$ Both the ps and aps duplexes display a very low sensitivity to Os,py under these conditons, but slight reactivity can be detected for the ps duplex on the original autoradiographs. ${ }^{d}$ High activity attributable to reaction with single strands formed upon dissociation of the duplex. ${ }^{e}$ Low reactivity, but the modification patterns of the same strand involved in the parallel or antiparallel duplex formation are different, ${ }^{f}$ Slightly decreased reactivity at higher salt concentration. ${ }^{g}$ Preferred cutting sites are the TAT steps.

Our results obtained with ss oligonucleotides most likely reflect formation of transient and partially paired duplexes in solution. Antiparallel species with 14 or less paired bases can be drawn for the D series of oligonucleotides (Rippe et al., 1989).

\section{CONCLUSIONS}

The spectroscopic, thermodynamic, and substrate properties of ps duplexes formed from synthetic oligonucleotides, including those used in this study (D1, D2, D3, and D4), have been described in previous reports (Ramsing \& Jovin, 1988; Rippe et al., 1989; Ramsing et al., 1989; Rippe \& Jovin, 1989; Jovin et al., 1990). It has also been shown that parallelstranded DNA can be formed by using oligonucleotides with incorporated dG and dC nucleotides (Rippe et al., 1990). Next to B-DNA, ps-DNA seems to be the most stable right-handed 

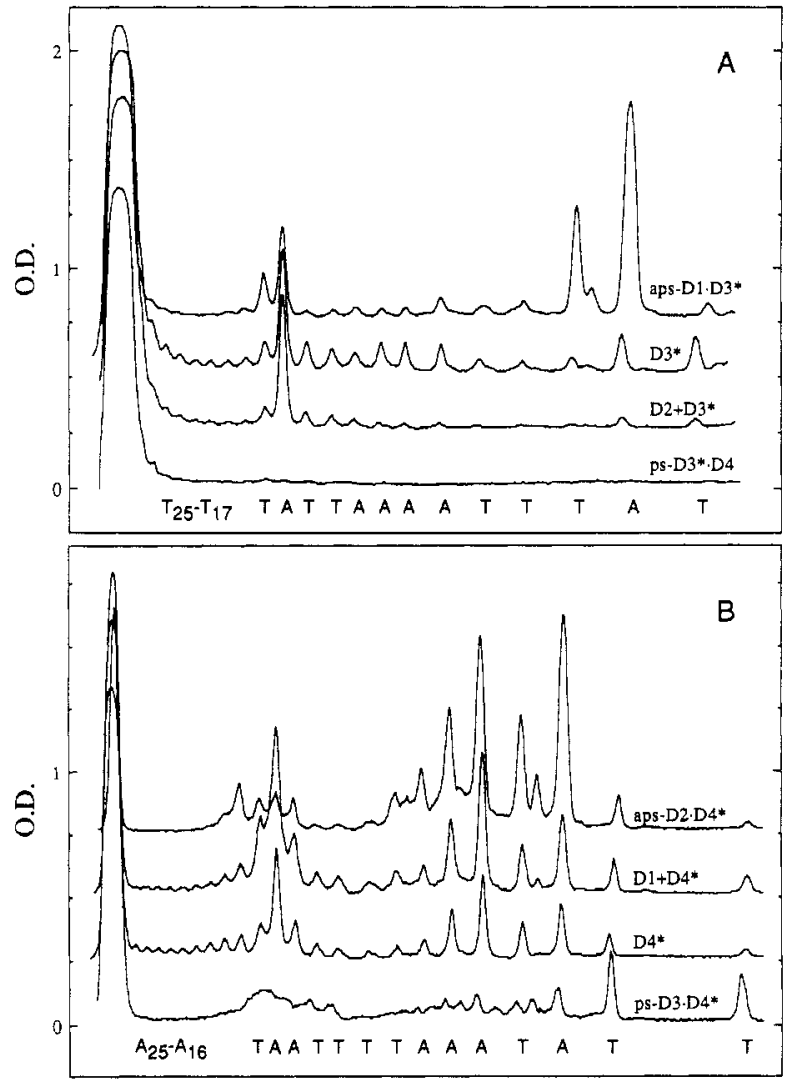

FIGURE 7: Copper-phenanthroline [(OP $\left.{ }_{2} \mathrm{Cu}^{+}\right]$cleavage pattern of ps, aps, and nonpairing combinations of labeled D3* and D4*. The figure shows densitometric scans of an autoradiograph of the DNA sequencing gel on which the reaction products were separated. The assignment of the peaks was derived from the migration of the Maxam-Gilbert sequencing products. (A) Strand D3* labeled. (OP) ${ }_{2} \mathrm{Cu}^{+}$cleavage pattern of ps-D3*.D4, aps-D1.D3*, D2 + D3* (nonpairing combination), and D3*. (B) Strand D4* labeled. (OP) ${ }_{2} \mathrm{Cu}^{+}$cleavage pattern of ps-D3.D4*, aps-D2.D4*, DI + D4* (nonpairing combination), and $\mathrm{D} 4 *$.

helical conformation known to date which can be readily achieved under physiological conditions. The dramatic structural differences of ps duplexes as compared with B-DNA are consistent with the chemical modification properties monitored with single-nucleotide resolution as described in this report. All of the chemicals employed can be used to ascertain if a given strand is single-stranded or is involved in aps or ps duplex formation, as summarized in Table I. Os,py has a slightly higher reactivity for the ps than the aps duplex at low salt concentration. Under high-salt conditions, the same reagent overreacts with the ps but not the aps duplex, an effect we attribute to a destabilization of the helix and a parallel increase in single-strand reactivity. DEPC distinguishes between the ss and duplex states of DNA and exhibits different patterns of modification within a given sequence in the ps and aps conformations. $\mathrm{KMnO}_{4}$ exhibits a selectivity similar to that of Os,py. Finally, $(\mathrm{OP})_{2} \mathrm{Cu}^{+}$reveals specific cleavage patterns in the case of aps-DNA but does not attack ps-DNA, presumably because the latter conformation lacks the specific minor groove stereochemistry of B-DNA.

The synthetic oligonucleotides of the D series (D1, D2, D3, and D4) are particularly suitable for studies of structural properties reflected at the level of single residues. We have demonstrated that the modification property of a given sequence can be determined in the single-stranded state and compared to its chemical susceptibility either in the aps or in the ps duplex. Thus, this work further evaluates and extends the methodological arsenal that can be applied to distinguish between aps-, ps-, and ss-DNAs in solution, particularly in the case of defined oligonucleotides. It is worth noting that the present approach may be useful in a more general way since it reduces substantially the amount of material required for distinguishing between conformations below that employed with spectroscopic techniques. In addition, it may serve to derive certain thermodynamic parameters such as $T_{\mathrm{m}}$ values in cases where a spectroscopic determination is not feasible because of the presence of highly ultraviolet-absorbing substances (e.g., solvents and drugs) in the sample.

\section{ACKNOWLEDGMENTS}

We thank G. Heim for technical assistance and Dr. E. Paleček for critical reading of the manuscript.

Registry No. D1 + D2, 123411-22-3; D3 + D4, 123411-23-4; D1 + D3, 123411-24-5; D2 + D4, 123411-25-6; D1, 123411-18-7; D2, 123411-19-8; D3, 123411-20-1; D4, 123411-21-2; DEPC, 1609-47-8; $(\mathrm{OP})_{2} \mathrm{Cu}^{+}, 17378-82-4 ; \mathrm{KMnO}_{4}, 7722-64-7 ; \mathrm{NaCl}, 7647-14-5 ; \mathrm{MgCl}_{2}$, 7786-30-3.

\section{REFERENCES}

Bhattacharya, A., \& Lilley, D. M. J. (1989) Nucleic Acids Res. 17, 6821-6840.

Borowiec, J. A., Zhang, L., Sasse-Dwight, S., \& Gralla, J. D. (1987) J. Mol. Biol. 196, 101-111.

Furlong, J. C., \& Lilley, D. M. J. (1986) Nucleic Acids Res. 14, 3995-4007.

Galazka, G., Paleček, E., Wells, R. D., \& Klysik, J. (1986) J. Biol. Chem. 261, 7093-7098.

Germann, M. W., Kalish, B. W., \& van de Sande, J. M. (1988) Biochemistry 27, 8302-8306.

Germann, M. W., Vogel, H. J., Pon, R. T., \& van de Sande, J. M. (1989) Biochemistry 28, 6220-6228.

Hanvey, J. C., Klysik, J., \& Wells, R. D. (1988) J. Biol. Chem. 263, 7386-7396.

Hanvey, J. C., Shimizu, M., \& Wells, R. D. (1989) J. Biol. Chem. 264, 5950-5956.

Herr, W. (1985) Proc. Natl. Acad. Sci. U.S.A. 82, 8009-8013. Johnston, B. H., \& Rich, A. (1985) Cell 42, 713-724.

Jovin, T. M., Rippe, K., Ramsing, N. B., Klement, R., Elhorst, W., \& Vojtišsková, M. (1990) in Proceedings of the Sixth Conversion in Biomolecular Stereodynamics, Structure \& Methods (Sarma, R. H., \& Sarma, M. H., Eds.) Vol. 3, pp 155-174, Adenine Press, Schenectady, NY.

Jovin, T. M., Soumpasis, D. M., \& Macintosh, L. P. (1987) Annu. Rev. Phys. Chem. 38, 521-560.

Klysik, J., Zacharias, W., Galazka, G., Kwinkowski, M., Uznanski, B., \& Okruszek, A. (1988) Nucleic Acids Res. 16, 6915-6933.

Kuwabara, M., Yoon, C., Goyne, T., Thederahn, T., \& Sigman, D. S. (1986) Biochemistry 25, 7401-7408.

Lilley, D. M. J., \& Paleček, E. (1984) EMBO J. 3, 1187-1192.

Lukâšovâ, E., Jelen, F., \& Paleček, E. (1982) Gen. Physiol. Biophys. 1, 53-70.

Lyamichev, V. I., Mirkin, S. M., Danilevskaya, O. N., Voloshin, D. N., Balatskaya, S. V., Dobrynin, V. N., Filipov, S. A., \& Frank-Kamenetskii, M. D. (1989) Nature 339, 634-637.

Maniatis, T., Fritsch, E. F., \& Sambrook, J. (1982) Molecular Cloning, A Laboratory Manual, Cold Spring Harbor Laboratory, Cold Spring Harbor, NY.

Nejedlý, K., Kwinkowski, M., Galazka, G., Klysik, J., \& Paleček, E. (1985) J. Biomol. Struct. Dyn. 3, 467-478.

Parniewski, P., Galazka, G., Wilk, A., \& Klysik, J. (1989) Nucleic Acids Res. 17, 617-629. 
Pattabiraman, N. (1986) Biopolymers 25, 1603-1606.

Paleček, E., Boublikovâ, P., Galazka, G., \& Klysik, J. (1987) Gen. Physiol. Biophys. 6, 327-341.

Paleček, E., Boublikovă, P., Jelen, F., Krejcova, A., Makaturova, E., Nejedlȳ, K., Pecinka, P., \& Vojtiškovā, M. (1990) in Proceedings of the Sixth Conversation in Biomolecular Stereodynamics, Structure \& Methods (Sarma, R. H., Sarma, M. H., Eds.) Vol. 3, pp 237-253, Adenine Press, Schenectady, NY.

Pope, L., \& Sigman, D. S. (1984) Proc. Natl. Acad. Sci. U.S.A. 81, 3-7.

Ramsing, N. B., \& Jovin, T. M. (1988) Nucleic Acids Res. 16, 6659-6676.

Ramsing, N. B., Rippe, K., \& Jovin, T. M. (1989) Biochemistry 28, 9528-9535.

Rich, A., Nordheim, A., \& Wang, A. J.-H. (1984) Annu. Rev. Biochem. 53, 791-846.

Rippe, K., \& Jovin, T. M. (1989) Biochemistry 28, 9542-9549.

Rippe, K., Ramsing, N. B., \& Jovin, T. M. (1989) Biochemistry 28, 9536-9541.

Rippe, K., Ramsing, N. B., Klement, R., \& Jovin, T. M. (1990) J. Biomol. Struct. Dyn. 7, 1199-1209.

Shchyolkina, A. K., Lysov, Y. P., Il'ichova, I. A., Chernyi, A. A., Golova, Y. B., Chernov, B. K., Gottikh, B. P., \&
Florentiev, V. L. (1989) FEBS Lett. 244, 39-42.

Sholten, P. M., \& Nordheim, A. (1986) Nucleic Acids Res. 14, 3981-3993.

Sigman, D. S. (1986) Acc. Chem. Res. 19, 180-186.

Sigman, D. S., \& Spassky, A. (1989) in Nucleic Acids and Molecular Biology (Eckstein, F., \& Lilley, D., Eds.) Vol. 3, pp 13-27, Springer-Verlag, Heidelberg.

Sigman, D. S., Spassky, A., Rimsky, S., \& Buc, H. (1985) Biopolymers 24, 183-197.

Tchurikov, N. A., Chernov, B. K., Golova, Y. B., \& Nechipurenko, Y. D. (1989) FEBS Lett. 257, 415-418.

van de Sande, J. H., Ramsing, N. B., German, M. W., Elhorst, W., Kalish, B. W., Kitzing, E., Pon, R. T., Clegg, R. M., \& Jovin, T. M. (1988) Science 241, 551-557.

Veal, J. M., \& Rill, R. L. (1988) Biochemistry 27, 1822-1827.

Vojtiškovä, M., \& Paleček, E. (1987) J. Biomol. Struct. Dyn. 5, 283-296.

Vojtís̆ková, M., Mirkin, S., Lyamichev, V., Voloshin, O. N., Frank-Kamenetskii, M. D., \& Paleček, E. (1988) FEBS Lett. 234, 295-299.

Voloshin, O. N., Mirkin, S. M., Lyamichev, V. I., Belotserkowskii, B. P., \& Frank-Kamenetskii, M. D. (1988) Nature 333, 475-476.

Yeung, A. T., Dinehart, W. J., \& Jones, B. K. (1988) Nucleic Acids Res. 16, 4539-4554.

\title{
Metabolism of the Carbocyclic Nucleoside Analogue Carbovir, an Inhibitor of Human Immunodeficiency Virus, in Human Lymphoid Cells ${ }^{\dagger}$
}

\author{
Laureano L. Bondoc, Jr., ${ }^{\ddagger}$ William M. Shannon, ${ }^{\S}$ John A. Secrist III, ${ }^{\S}$ Robert Vince, and Arnold Fridland*, \\ Department of Biochemical and Clinical Pharmacology, St. Jude Children's Research Hospital, 332 N. Lauderdale, P.O. Box \\ 318. Memphis, Tennessee 38101, Southern Research Institute, Birmingham, Alabama 35455, and Department of Medicinal \\ Chemistry, College of Pharmacy, Health Sciences Unit F, University of Minnesota, Minneapolis, Minnesota 55455 \\ Received May 14, 1990; Revised Manuscript Received August 1, 1990
}

\begin{abstract}
Carbovir (CBV) is a highly selective carbocyclic nucleoside inhibitor of HIV replication in human lymphocytes and is potentially useful in the treatment of AIDS [Vince et al. (1988) Biochem. Biophys. Res. Commun. 156, 1046-1053]. Using human lymphoid cells severely deficient in nucleoside kinases, we were able to identify the route of activation of CBV metabolism. The present studies have demonstrated that CBV is anabolized to the mono-, di-, and triphosphates and to guanosine $5^{\prime}$-triphosphate in CCRF-CEM cells. Conversion to GTP amounted to $15-20 \%$ of the total analogue nucleotides formed in the cells and may arise from CBV through depurination and salvage via HGPRT. Evidence was obtained that neither deoxycytidine kinase, adenosine kinase, or mitochondrial deoxyguanosine kinase is primarily involved in the initial step of phosphorylation of CBV in CCRF-CEM cells. In contrast, earlier studies [Johnson \& Fridland (1989) Mol. Pharmacol. 36, 291-295] showed that a cytosolic 5'-nucleotidase catalyzes the activation of CBV to the monosphosphate. Other biochemical effects examined showed that the nucleobases hypoxanthine and adenine, but not guanine, their respective nucleosides, and the dideoxynucleosides $2^{\prime}, 3^{\prime}$-dideoxyinosine, $2^{\prime}, 3^{\prime}$-dideoxyguanosine, and $3^{\prime}$-azido-3'-deoxythymidine produced significant increased accumulation of CBV nucleotides in CEM cells. The exact mechanism for this potentiation of CBV phosphorylation has not been elucidated but may be due to a modulating effect of intracellular nucleotides on 5 -nucleotidase activity.
\end{abstract}

$T_{\text {h }}$ 2' 3'-didehydro-2' 3'-dideoxyuanosine NSC-614846, CBV) is a novel guanosine derivative which has shown potent in vitro

\footnotetext{
${ }^{+}$Supported in part by PHS Grants 1 R01 CA43296 and AI27652 and CORE Grant P30 CA21765 from the National Institutes of Health and by the American Lebanese Syrian Association Charities.

tSt. Jude Children's Research Hospital.

Southern Research Institute.

"University of Minnesota.
}

activity against the human immunodeficiency virus, the etiological agent of AIDS. CBV inhibits HIV replication and

\footnotetext{
'Abbreviations: CBV, carbovir; HIV, human immunodeficiency virus; AIDS, autoimmune deficiency syndrome; AZT, 3'-azido-3'-deoxythymidine; ddC, 2',3'-dideoxycytidine; TP, 5'-triphosphate; ddNTP $2^{\prime}, 3^{\prime}$-dideoxynucleoside $5^{\prime}$-triphosphate; HPLC, high-pressure liquid chromatography; HGPRT, hypoxanthine-guanine phosphoribosyltransferase; ddG, $2^{\prime}, 3^{\prime}$-dideoxyguanosine; dGuo, 2'-deoxyguanosine; PNP, purine nucleoside phosphorylase.
} 